\title{
The reliability of preference for signaled shock
}

\author{
PAUL LEWIS and EDWARD T. GARDNER \\ Ohio University, Athens, Ohio 45701
}

\begin{abstract}
Furedy and Biederman cited unreported silent parameters as the reason for their failure to replicate one of Badia and Culbertson's (1972) experiments. Badia and Culbertson reported that rats prefer signaled electric shock to unsignaled. The purpose of the present experiment was to determine if the preference for signaled shock would emerge, using the Badia and Culbertson procedure, in a different laboratory and, hence, to evaluate the Furedy and Biederman speculation about silent parameters. Rats were shocked, in one of two conditions, at unpredictable times throughout each session. In the signaled conditions, each shock was preceded by a tone; in the unsignaled condition, no shock was preceded by a tone. Later, when given the opportunity, each rat changed the unsignaled condition to the signaled condition. The results are very similar to those of Badia and Culbertson. It was concluded that the changeover procedure is valid, reliable, and interpretable.
\end{abstract}

Badia and Culbertson (1972) reported that rats prefer signaled shock. In that study, rats received electric shocks delivered in one of two conditions. In a signaled condition, a warning signal preceded each shock; in an unsignaled condition, no warning signal was given. Later, rats were given a choice between the signaled and the unsignaled conditions. In the choice procedure, a rat could, by pressing a lever, change from the unsignaled condition to the signaled. Badia and Culbertson (1972) reported that seven rats changed from the unsignaled to the signaled condition and allocated approximately $90 \%$ of each session to the latter condition.

Preference for signaled shock has been observed many times in different situations (Arabian \& Desiderato, 1975; Badia \& Culbertson, 1972; Fisher \& Badia, 1975; Lanzetta \& Driscoll, 1966; Lockard, 1963; Perkins, Levis, \& Seyman, 1963). However, in recent years, several investigators have failed to observe the preference (Furedy \& Doob, 1972; Furedy \& Ginsberg, 1973; Furedy \& Klajner, 1972) or have failed to observe the preference with unmodifiable shock (Biederman \& Furedy, 1970, 1976).

Most surprising, Biederman and Furedy (1976), using a procedure described as identical to that of Badia and Culbertson (1972, Experiment 2), observed preference for signaled shock in only 1 of 14 rats.

Furedy and Biederman (Note 1) attribute their failure to observe a preference for signaled shock to "silent parameters." Silent parameters are unreported characteristics of equipment (dimensions, etc.) and undescribed procedures (handling, feeding schedule, etc.) routinely

This research was supported by NIMH Grant 1R01 MH 9593-1 to Ohio University. The authors thánk Gary Echt and Jean Ries for help in collecting the data. A presentation based on these data was given at the Psychonomic Society meetings, 1975 , in Denver. Reprints may be obtained from Paul Lewis, Department of Psychology, Porter Hall, Ohio University, Athens, Ohio 45701. employed in a particular laboratory. Furedy and Biederman suggest that one or more silent parameters in Professor Badia's laboratory was responsible for the rats preference for signaled shock (Badia \& Culbertson, 1972). Because of the nature of the concept of silent parameters, it is difficult to evaluate their influence experimentally. However, if silent parameters are minor and arbitrary details employed in a particular research setting, it is reasonable to suppose that research settings will differ naturally in this regard.

The present experiment repeated the Badia and Culbertson (1972) experiment to evaluate Furedy and Biederman's claim that the preference for signaled shock, observed with the changeover procedure, was the result of silent parameters in the Bowling Green laboratory.

\section{METHOD}

\section{Subjects}

Six naive female albino rats of the Sprague-Dawley strain, purchased from the Holtzman Company, were approximately 90 days old at the start of the experiment and had free access to food and water in their home cages.

\section{Apparatus}

Each subject was tested in a two-lever operant-conditioning chamber $24.2 \times 30.5 \times 24.1 \mathrm{~cm}$ high. A clear plastic ceiling, $.6 \mathrm{~cm}$ thick, was mounted $10.8 \mathrm{~cm}$ above the grid bars and $2.9 \mathrm{~cm}$ above the response levers. The two side walls were clear plastic. The front and rear walls were stainless steel. Two Gerbrands rat levers, requiring approximately $20 \mathrm{~g}(.2 \mathrm{~N})$ to depress, were mounted on the front $(24.1 \mathrm{~cm})$ wall $2.9 \mathrm{~cm}$ from each side and $7.9 \mathrm{~cm}$ from the grid bars. Depression of either lever served as a response. A $1,400-\mathrm{Hz}$ tone $(86 \mathrm{~dB})$ served as a preshock warning stimulus. Offset of a $1.3-\mathrm{cm}$ white jeweled light $(24 \mathrm{~V})$ mounted above the left bar signaled the beginning of the session; its onset signaled the end of the session. For some animals, illumination of a $1.3-\mathrm{cm}$ white jeweled light $(24 \mathrm{~V})$ mounted above the right lever served as a correlated stimulus; for other animals, the light was extinguished as the correlated stimulus.

The chamber, enclosed in an acoustical box, was modified so that the grid bars were perpendicular to the wall on which the response levers were mounted. Grid bars were .48 -cm stainless 
steel and spaced $1.6 \mathrm{~cm}$ apart center to center. A BRS solid state shock source delivered a $75-\mathrm{mW}$ shock of $.5-\mathrm{sec}$ duration to grids, front and rear walls, and response levers. All shocks were scrambled. Solid state switching circuits housed in an adjacent room controlled all events. Responses stepped a Gerbrand's cumulative recorder.

\section{Procedure}

Sessions were $6 \mathrm{~h}$ and occurred every other day. Shocks were delivered on the average of once every $120 \mathrm{sec}$ (variable-time 120 -sec or VT 120-sec) in all conditions throughout all sessions. The VT had intershock intervals ranging from 30 to $210 \mathrm{sec}$ in $30-\mathrm{sec}$ blocks. For $2.5 \mathrm{sec}$ following the onset of each shock, responses were ineffective in changing conditions; this is known as a 2.5 -sec postshock changeover delay (COD). Described below are several procedures that were administered (see Figure 1 for the order in which the procedures occurred). Subjects were continued on a procedure until their performance appeared stable in the cumulative records.

Initial training. Badia and Culbertson (1972) used, for different groups, two types of initial training: (1) signaled shocks only or (2) a multiple schedule involving a signaled-shock component and an unsignaled-shock component. We used the multiple schedule only. The signaled- and unsignaled-shock components, $1 \mathrm{~h}$ in length, alternated throughout the session. For four subjects (B1, B2, B4, and B5), the stimulus correlated with the signaled component was light on; for two subjects (B3 and B6), the correlated stimulus was light off. During initial training, for each subject, responses and the time that would have been spent in the alternate condition were recorded, but those responses produced no stimulus change.

Changeover for signaled shock (changeover). Following initial training, subjects were exposed to the changeover (choice) procedure. In the absence of a response, the unsignaled condition was in effect. A leverpress resulted in the onset of the signaled condition and the onset of the correlated stimulus for $3 \mathrm{~min}$. Additional responses within the $3 \mathrm{~min}$ were ineffective. At the end of the $3 \mathrm{~min}$, the unsignaled schedule was reinstated. At that time, the rat could remain in the unsignaled condition or (by pressing a lever) could reinstate the signaled condition.

Changeover Extinction 1 (EXT 1). A barpress had no effect. A response activated neither the correlated stimulus nor the warning stimulus.

Changeover Extinction 2 (EXT 2). A barpress activated the correlated stimulus for $3 \mathrm{~min}$, but the warning stimulus never preceded shock.

Changeover Extinction 3 (EXT 3). A barpress was followed by $3 \mathrm{~min}$ during which the warning stimulus preceded shock; however, the correlated stimulus was not activated during the 3 min signaled-shock period.

Symmetrical changeover (SCO). Three naive subjects (B4, B5, and B6) and two previously trained subjects (B1 and B2) were exposed to a symmetrical choice procedure. In the symmetrical changeover schedule, the prevailing condition (signaled or unsignaled) was terminated, and the "other" condition was introduced every $3 \mathrm{~min}$ throughout each session. In addition, each response terminated the prevailing condition and activated the other condition.

\section{RESULTS}

Figure 1 shows, for each of three subjects (B1, B2, and B3) and for each of the last 3 days of each condition, the percent of the session spent in the alternate condition. Under the initial training (baseline), all three subjects spent low percentages of time in the "changeover condition." During the initial exposure to the changeover ( $\mathrm{CO})$ procedure, all subjects began changing from the unsignaled to the signaled condition. On the second through the fourth days of the $\mathrm{CO}$ procedure, each subject allocated $80 \%-96 \%$ of the session to the signaled condition. When responding was ineffective in activating the signaled condition (EXT 1), the time allocated to the $\mathrm{CO}$ condition decreased for all subjects. On the second exposure to the $\mathrm{CO}$ schedule, percent of time spent in the alternate condition returned to over $80 \%$. When responding resulted in the onset of the correlated stimulus, but in no warning signal (EXT 2), percent of time spent in the alternate condition remained at a high level (68\%-97\%). On the third exposure to the $\mathrm{CO}$ condition, the subjects continued to allocate more than $80 \%$ of the $6-\mathrm{h}$ sessions to the signaled condition. Finally, when responding resulted in a 3-min period during which shocks were signaled, but no correlated stimulus was present (EXT 3), percent of time in the signaled condition decreased to less than $45 \%$. Subject B3 died on the day following Session 35 .

For Subjects B4, B5, and B6 in the four sessions of the multiple training schedule and in the four sessions of the symmetrical changeover condition (SCO), Fig-

Figure 1. Percent of session time spent in changeover for the last three sessions of each condition. Conditions appear in the order administered.

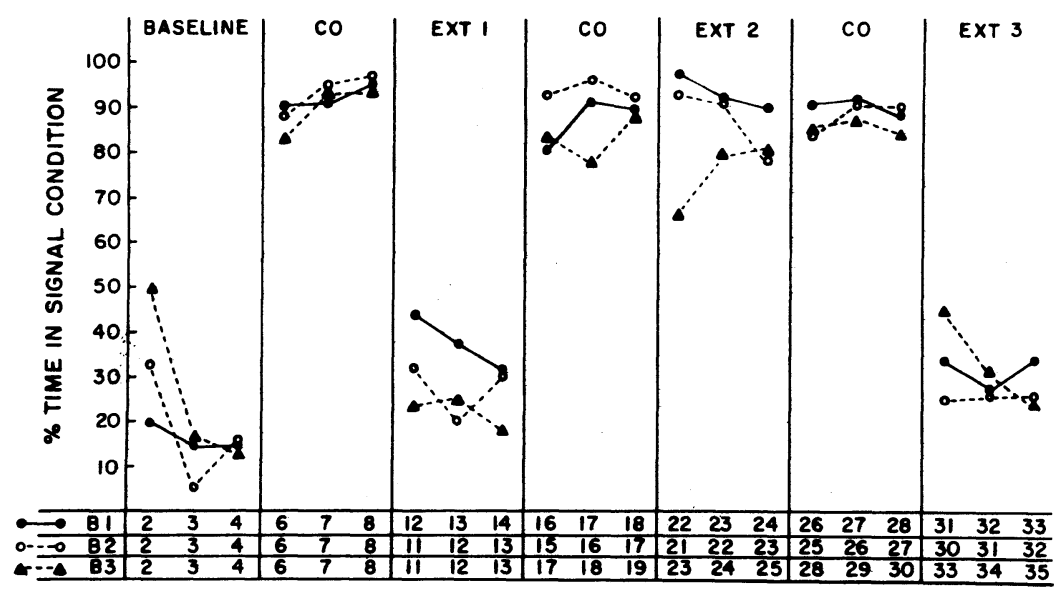




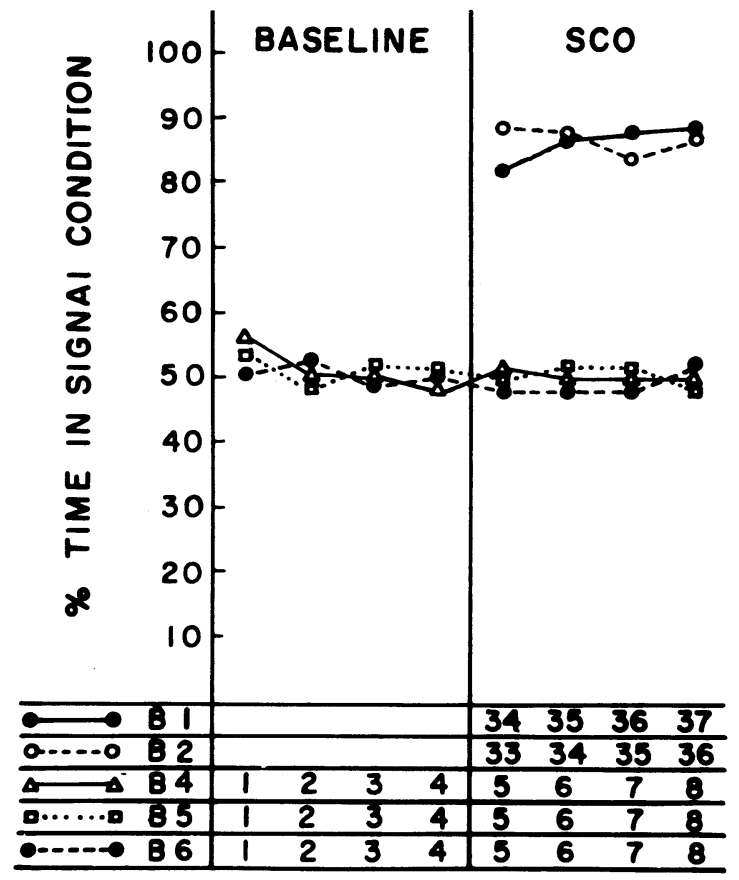

SIX HOUR SESSIONS

Figure 2. Percent of session time spent in changeover for all sessions of the baseline and symmetrical changeover procedures. Conditions appear in the order administered. Subjects B1 and B2 were placed directly on the symmetrical changeover procedure following EXT 3 shown in Figure 1.

ure 2 shows the percent of time spent in the CO condition. In addition, Figure 2 shows the performance of Subjects B1 and B2 on four sessions of exposure to SCO. The three animals (B4, B5, and B6) given the multiple training prior to the SCO condition failed to exhibit a preference. Under both the multiple (baseline) condition and the SCO condition, subjects B4, B5, and B6 spent approximately $50 \%$ of the total session in the $\mathrm{CO}$ condition. In contrast, the two subjects (B1 and B2) given prior exposure to all the Badia and Culbertson (1972) conditions spent approximately $80 \%-90 \%$ of the session in the signaled condition.

\section{DISCUSSION}

The present findings replicated those reported by Badia and Culbertson (1972). Figure 3 shows percent of time in the signaled condition for the five conditions of Badia and Culbertson's experiment and for the present experiment. The results are very similar.

Furedy and Biederman's conclusion (Note 1) that Badia and Culbertson's (1972) findings are not repeatable is contradicted by the present results. The present experiment provides no support for the operation of "silent parameters."

Biederman and Furedy (1970) also question the validity of data collected with the changeover procedure, even if the data were reliable. For three reasons, say Furedy and Biederman, (choice-response asymmetry, asymmetrical effects of the behaviors measuring preference, stimulus-change confounding), the changeover procedure is not a valid measure of choice. Furedy and Biederman contend that the changeover procedure is asymmetrical in two ways. First, the response that produces the signaled condition is different from the response that produces the unsignaled condition (choice-response asymmetry). A barpress leads to the signaled condition, whereas witholding a barpress leads to the unsignaled condition. Second, the effects of the responses are not the same (asymm.etrical effects of the behaviors measuring preference). The response that produces the signaled schedule produces a stimulus, a change in illumination. The response that produces the unsignaled schedule does not produce a stimulus. Finally, Furedy and Biederman point out that a changeover response produces a change in illumination as well as the signaled condition (stimulus-change confounding); thus, the response may be strengthened by photic reinforcement (Kish, 1966), not by the relationship between the illumination condition and the signal. In the foregoing criticisms, Furedy and Biederman have offered an "explanation" for the observed increases in barpressing other than the one offered by Badia and Culbertson (1972). Badia and Culbertson claim the leverpress occurs because it produces a correlated stimulus and a tone before each shock.

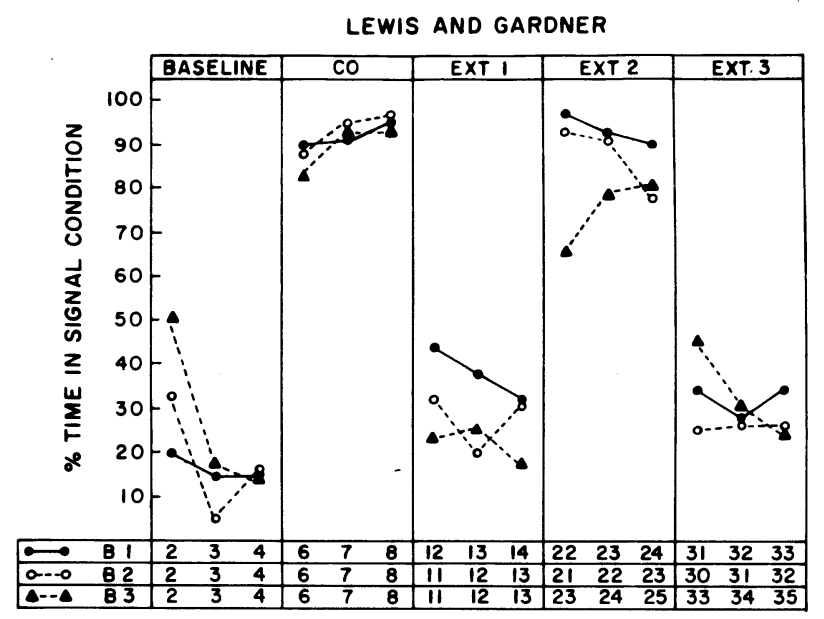

SIX HOUR SESSIONS

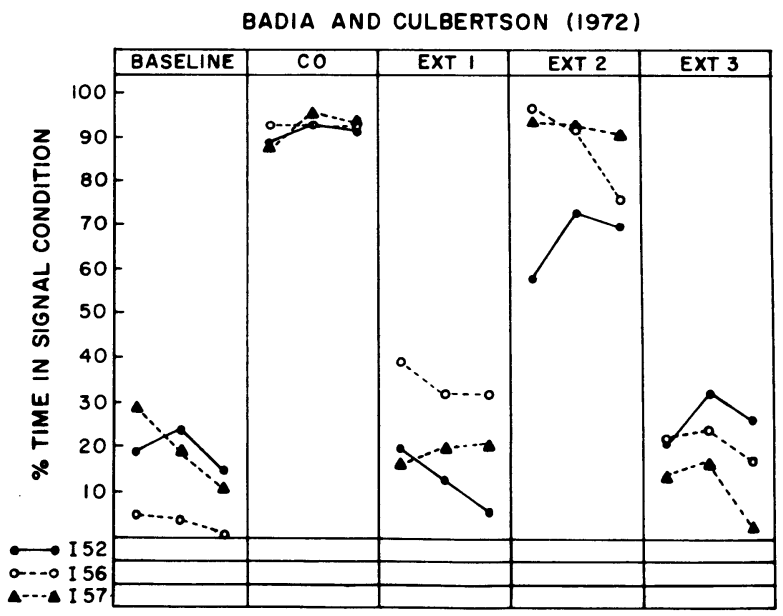

SIX HOUR SESSIONS

Figure 3. Percent of session time spent in changeover for the last 3 days of initial exposure to each condition. The lower graph shows data presented by Badia and Culbertson (1972); the upper graph shows comparable data collected in the present study. Session numbers are not available from the Badia and Culbertson (1972) report. 
Furedy and Biederman have correctly identified three characteristics of the changeover procedure, but have incorrectly concluded that those characteristics represent obstacles to the interpretation of data collected with the changeover procedure. The validity of each of the three criticisms could be evaluated in a procedure in which rats are placed in the signaled condition and permitted to change over to the unsignaled condition. According to the two asymmetry criticisms, rats should change over to the unsignaled condition because of the asymmetry of the response and the asymmetry of the feedback from the response. According to the stimulus-change hypothesis, rats should change over because the change to the unsignaled condition would be accompanied by a change in illumination. Badia, Harsh, and Coker (1975) have presented data relevant to these predictions.

In the Badia et al. study (1975), rats chose between two inescapable, unavoidable shock conditions. In one condition, brief shocks were delivered every $60 \mathrm{sec}$ (FT $60 \mathrm{sec}$ ); in the other, shocks were delivered on the average every $60 \mathrm{sec}$, but at variable times (VT $60 \mathrm{sec}$ ). By pressing a bar, animals changed from the VT $60-\mathrm{sec}$ schedule to the FT $60-\mathrm{sec}$ schedule for a period of 3 min (Experiment 1). Badia et al. (1975) found that nine out of nine subjects changed over, showing a preference for the FT 60 -sec schedule. In Experiment 2, shocks from the VT 60 -sec schedule were signaled by a 5 -sec tone. Signaling the VT shocks reversed the preference; rats preferred signaled VT shocks to unsignaled FT shocks. In both experiments Badia et al. (1975) reversed the conditions as a control procedure and allowed the subjects to change from the more preferred to the less preferred condition. According to all three of Furedy and Biederman's (Note 1) criticisms, responding should have continued under the control conditions because (1) the response was still asymmetrical, (2) the feedback for responding was still asymmetrical, and (3) the response produced a stimulus change. However, the animals did not respond under the control conditions reported by Badia et al. (1975), thus failing to support predictions based on Furedy and Biederman (Note 1).

In the present experiment a symmetrical changeover procedure was studied to examine preference for signaled shock when the same leverpress produced the signaled and the unsignaled shock condition (symmetrical). As evident from Figure 2, Subjects B1 and B2 strongly preferred signaled shock; however, because the three naive animals (B4, B5, and B6) failed to develop a preference for signaled shock after $24 \mathrm{~h}$ of training and $24 \mathrm{~h}$ of testing, this particular symmetrical procedure appears inferior to the changeover procedure.

The symmetrical changeover data allow two conclusions. First, preference for signaled shock can be demonstrated using a procedure that is fully symmetrical. Second, some aspects of the extended experience of Subjects B1 and B2 is necessary before the preference can be observed in the symmetrical changeover procedure.

In addition to their three criticisms, Biederman and Furedy $(1970,1976)$ contend that preference for signaled shock is observed only when shocks are modifiable, that is, can be reduced in duration or intensity by some response. In the present experiment, as well as in that by Badia and Culbertson (1972), the grid scrambler prevented the rats from modifying shock in any important way. More convincing are experiments by Miller, Daniel, and Berk (1974); Griffin, Honaker, Jones, and Pynes (1974); and Fisher and Badia (1975). The shock delivery system employed by these investigators prevented subjects from modifying the shock. Miller et al. delivered shock through electrodes firmly attached to rats' tails; Griffin et al. delivered shock through electrodes surgically implanted around pigeons' pubis bones; Fisher and Badia delivered shock through water to the surface of goldfish. All these studies found preference for signaled over unsignaled shock. These studies provide evidence against Furedy and Biederman's contention that the preference for signaled shock occurs only with modifiable shock.

The successful replication in the present report shows the reliability of the Badia and Culbertson experiment and implies that minor aspects of handling and equipment (silent parameters) are inadequate to account for Furedy and Biederman's failure to replicate Badia and Culbertson (1972).

\section{REFERENCE NOTE}

1. Furedy, J. J., \& Biederman, G. B. Methodological problems in evaluating rat preference for signaled or unsignaled shock. Paper presented at the meeting of the Psychonomic Society. Boston, November 1974.

\section{REFERENCES}

Arabian, J. M., \& Desiderato, O. Preference for signaled shock: A test of two hypotheses. Animal Learning \& Behavior, 1975, 3, 191-195.

Badia, P., \& Culbertson, S. The relative aversiveness of signaled vs. unsignaled escapable and inescapable shock. Journal of the Experimental Analysis of Behavior, 1972, 17, 463-471.

Badia, P., Culbertson, S., \& Harsh, J. The relative aversiveness of signaled and unsignaled shock situations in humans. Journal of Comparative and Physiological Psychology, 1974, 87, 338-346.

Badia, P., Harsh, J., \& Coker, C. C. Choosing between fixed time and variable time shock. Learning and Motivation, $1975,6,264-278$.

Biederman, G. B., \& Furedy, J. J. The preference-forsignaled-shock phenomenon: Signaling shock is reinforcing only if shock is modifiable. The Quarterly Journal of Experimental Psychology, 1970, 22, 681-685.

Biederman, G. B., \& Furedy, J. J. Operational duplication without behavioral replication of changeover for signaled inescapable shock. Bulletin of the Psychonomic Society, 1976, 7, 421-424.

Fisher, C., \& BADia, P. Preference for signaled or unsignaled shock in goldfish. Bulletin of the Psychonomic Society, 1975, 2, 195-197.

Furedy, J. J., \& Dоов, A. N. Signaling unmodifiable shock: Limits on human informational cognitive control. Journal of Personality and Social Psychology, 1972, 21, 111-115.

Furedy, J. J., \& GinsBerg, S. Effects on varying signaling and intensity of shock on an unconfounded and novel electrodermal autonomic index in a variable- and longinterval classical trace conditioning paradigm. Psychophysiology, 1973, 10, 328-334.

Furedy, J. J., \& KlaJNer, F. Unconfounded autonomic indexes of the aversiveness of signaled and unsignaled shocks. Journal of Experimental Psychology, 1972, 92, 313-318.

Griffin, P., Honaker, L. M., Jones, D. E., \& Pynes, L. T. Preference for signaled vs. unsignaled shock in pigeons with implanted electrodes. Bulletin of the Psychonomic Society, 1974, 4, 114-143.

KIsH, G. B. Studies of sensory reinforcement. In W. K. Honig (Ed.), Operant behavior: Areas of research and application. New York: Appleton-Century-Crofts, 1966.

Lanzetta, J. T., \& Driscoll, J. M. Preference for information about an uncertain but unavoidable outcome. Journal of Personality and Social Psychology, 1966, 3, 96-102.

LOCKARD, J. S. Choice of a warning signal or no warning signal in an unavoidable shock situation. Journal of Comparative and Physiological Psychology, 1963, 56, 526-530.

Miller, R. R., Daniel, D., \& Berk, A. M. Successive reversals of a discriminated preference for signaled tailshock. Animal Learning \& Behavior, 1974, 2, 271-274.

Perkins, C. C., Jr., Levis, D. F., \& Seyman, R. Preference for signal-shock vs. shock-signal. Psychological Reports, 1963, 13, 735-738.

(Received for publication September 15, 1976.) 